\title{
EVALUATION OF SERUIM URIC ACID, SERUIM MAGNESIUM AND LIPID PROFILES IN TYPE 2 DIABETES MELLITUS PATIENTS FOR THE RISK FACTOR OF CARDIOVASCULAR DISEASE.
}

KEY WORDS: Cardiovascular disease, lipid profile, Magnesium, Type 2 Diabetes mellitus, Uric acid.

\section{Sonal Sogani*}

\section{Suman Jain}

Associate Professor, Department of Biochemistry, Pacific Institute of Medical Sciences, Udaipur (Raj.)-313015. *Corresponding Author

Associate Professor, Department of Biochemistry, Pacific Institute of Medical Sciences, Udaipur (Raj.)-313015.

Background \& Objective: Dyslipidemia is one of the common disorders which are seen in most of the diabetes patients, which causes cardio vascular diseases. However, serum uric acid and lipid profiles are considered as the potential risk factor for developing diabetes, hypertension, stroke and cardiovascular diseases. Also the direct association of trace elements such as serum magnesium and hs-CRP in type 2 diabetes has been observed. The aim of the present study is to evaluate serum uric acid, serum magnesium and lipid profiles in type 2 diabetes mellitus patients for the risk factor of cardiovascular disease and its comparison with non diabetic subjects. Material \& Methods: This case-control study was conducted in the Department of Biochemistry, PIMS, Udaipur. The study included 100 patients with type 2 Diabetes Mellitus (both males and females) who were recruited from the institute's medicine OPD and wards and 100 healthy controls (both males and females) with normal plasma glucose and with no symptoms suggestive of DM were included in the study. All the Biochemical parameters analysis was done on fully automated analyzer-ERBA 360 EM. Results: The mean values of serum lipid profile (serum cholesterol, serum triglycerides, VLDL, LDL) were compared between healthy controls and patients with type $2 \mathrm{DM}$, showed highly significant difference in patients with type $2 \mathrm{DM}$ as compared with healthy controls $(\mathrm{p}<0.001)$. However, on comparing HDL between healthy controls and patients with type $2 \mathrm{DM}$, the difference seems to be significant $(p<0.05)$. The mean values of RBS, HbAlc, uric acid and hs-CRP were highly significant in patients with type $2 \mathrm{DM}$ as compared with healthy controls $(\mathrm{p}<0.001)$. The mean values of serum magnesium showed significant difference between healthy controls and patients with type $2 \mathrm{DM} \mathrm{p}<0.05)$. Interpretation And Conclusion: The common lipid abnormalities seen during diabetes induce dyslipidemia causing the development of CVD's among diabetic patients. Also elevated levels of hs-CRP, hyperuricemia, hypomagnesium suggest that it could be a better prognosis for CVD's and stroke in diabetic patients.

\section{INTRODUCTION:}

India, a developing Asian country with fast industrialization and a modern lifestyle is facing a grave problem in having the largest number of people with diabetes. ${ }^{1}$ It is estimated that 194 million people of developing countries had diabetes in the year 2003. ${ }^{2}$ The world wide prevalence of DM had risen dramatically. As projected by the International Diabetes Federation, the global burden of type $2 \mathrm{DM}$ for 2010 would be 285 million people which are expected to increase to 438 million in 2030. ${ }^{3}, \quad$ By the year 2030, the greatest number of individuals with diabetes will be aged $45-64$ years. Although the prevalence of both type 1 and type $2 \mathrm{DM}$ is increasing worldwide, the prevalence of type $2 \mathrm{DM}$ is increasing much more rapidly due to increasing obesity and reduced activity levels. India is considered the diabetes capital of the world by $2020 \mathrm{AD}$. It is estimated that the prevalence of diabetes in rural population is $2-4 \%$ and in urban it is expected to be $11.6 \% .^{5}$

Type2 Diabetes mellitus (DM) is a metabolic and endocrinological disease which is characterized by hyperglycemia (increased blood glucose level) that results from defects in insulin secretion, insulin action or both. ${ }^{6}$ Also it is characterized by disturbances of carbohydrate, lipid and protein metabolism. ${ }^{7}$ The chronic hyperglycemia of diabetes is associated with damage of several body organs which could be the result of microvascular and macrovascular complications. ${ }^{8}$ Besides hyperosmolar coma and ketoacidosis, the microvascular complication in patients with type 2 diabetes mellitus include cardiovascular disease (CVD) such as heart disease and stroke which could be the cause of death in $50 \%$ of diabetics., ${ }^{9,10}$ The macrovascular complications of diabetes include diabetic neuropathy, nephropathy and retinopathy.

The cardiovascular risk of diabetes increases further if diabetes is associated with dyslipidemia. Dyslipidemia is well known and modified CVD risk factors for coronary heart disease that should be identified early. In type $2 \mathrm{DM}$ patients the risk of death from CVD is 2-5 times higher than in nondiabetic persons. World Health Organization (WHO) and
International Diabetes Federation (IDF) use the term "Metabolic Syndrome or Reaven's syndrome" to describe that type $2 \mathrm{DM}$ is associated with plasma lipid and lipid abnormalities which include a triad of abnormally high level of triglycerides (TG), high proportion of low density lipoprotein (LDL), low high density lipoprotein (HDL).$^{12}$ This pattern of lipid profile in type $2 \mathrm{DM}$ is termed as diabetic dyslipidemia or atherogenic dyslipidemia. ${ }^{13}$ However, it is suggested that the lipid particles composition in diabetic dyslipidemia is more atherogenic than other types of dyslipidemia. ${ }^{14}$ Other features of insulin resistance like hyperinsulinemia, essential hypertension hypercholesterolemia with central obesity that is strongly associated with atherosclerosis, is found in type $2 \mathrm{DM}$ patients. $^{15,16}$

Hemoglobin Alc (HbAlc) is a glycated hemoglobin which is formed by the non-enzymatic reaction of glucose with native hemoglobin. It is a suitable indicator for detecting the state of glycemic control, progress of disease, and disease complications in DM patients. ${ }^{17,18}$ It is routinely measured to check the glycemic control over a preceding 8-12 weeks of time. ${ }^{19} \mathrm{HbAlc}$ concentrations predict CVD risk in diabetic patients. The good blood glucose controls are associated with reduction in CVD and elevated $\mathrm{HbAlc}$ levels are associated with increasing CVD risk ${ }^{20}$ which is predicted to be increased by $18 \%{ }^{2}$

High sensitivity C-reactive protein (hs-CRP) is a liver derived acute phase protein that is increased in inflammatory state. It is measured by highly sensitive assay. It rapidly increases within hours after tissue injury or in inflammation and decreases more quickly than the erythrocyte sedimentation rate (ESR).

Also it is suggested to be a part of the innate immune system and contribute to host defense. Since cardiovascular disease is an inflammatory process, hs-CRP is considered to be associated with future major cardiovascular risk. ${ }^{22}$ 
Uric acid, the prime end product of purine catabolism and the precursor of gout, has been implicated in diabetes mellitus as well as in hyperlipidemias. There is a possible role of insulin in nucleotide metabolism. ${ }^{23,24}$ High uric acid is considered as an independent risk factor for developing diabetes, hypertension, stroke and CVDs. The clearance of UA is being reduced with increase in insulin resistance. ${ }^{25}$

Magnesium is an important second most divalent intracellular cation and the fourth most abundant cation in the human body. It is distributed into three major compartments: mineral phase of bones $(65 \%)$, intracellular space $(34 \%)$, and extracellular fluid (1\%). ${ }^{26}$ Magnesium is needed for more than 300 biochemical reactions in the body. It serves as a cofactor for all enzymatic reactions that requires kinases. It plays an important role in carbohydrate metabolism. It regulates the activity, secretion, binding and release of insulin, the latter helps in the control of blood glucose levels. ${ }^{27}$

Diabetes is one of the most leading causes of cardiovascular diseases. The current research that includes biochemical parameters such as serum uric acid, serum magnesium, hsCRP along with the lipid profile may help the diabetic patients for the reduction of the future risk of MI, Atheroscelorosis. These parameters are routinely done and are not expensive, so the diabetic patient may afford such tests and can be safe from the risk factors associated with dyslipidemia.

\section{MATERIAL AND METHODS:}

This case-control study was conducted in the Department of Biochemistry, Pacific Institute of Medical Sciences, Udaipur. The study included 100 patients with type 2 Diabetes Mellitus (both males and females) who were recruited from the institute's medicine OPD and wards and their diagnosis was confirmed by biochemical investigations as per American Diabetes Association (ADA) 2011, ${ }^{28}$ criteria 30 (based on consensus expert from National Data Diabetic Group and WHO).$^{29,30}$ Dyslipidemia was defined using the National Cholesterol Education Programme (NCEP) ATPIII guidelines. 100 healthy controls (both males and females) with normal plasma glucose and with no symptoms suggestive of DM were included in the study. The age criteria for both the groups were within 30-70 year. The inclusion criteria of the study included the patients with type 2 diabetes mellitus who were freshly diagnosed and who were already on treatment. The exclusion criteria of the study included the patients who were on drugs that contain calcium, phosphate and magnesium and those who are on diuretic therapy. Patients under the medications for hypertension. hyperuricemia, dyslipidemia are excluded from the study. Patients with chronic and acute inflammatory conditions, other metabolic conditions like ketoacidosis, cerebrovascular disease, primary hypertensive, and osteoporosis are not included in the study. Smokers and alcoholics are excluded from the study.

\section{Sample Collection:}

Blood samples taken for the analysis were obtained from patients and healthy subjects from anticubital veins. For estimating random blood sugar (RBS), blood sample was collected in the fluoride tube. For the HbAlc estimation, plasma sample was collected in EDTA vial. Serum sample for estimating Magnesium, Uric acid, hs-CRP and lipid profile was obtained by collecting blood sample in plane vial. Blood samples were separated from cells by centrifugation at 3000 rpm for 10 minutes.

\section{Assay For Biochemical Parameters:}

All the Biochemical parameters analysis was done on fully automated analyzer-ERBA 360 EM using the commercially available kits. Random blood sugar was measured using GHOD-POD method. Estimation of $\mathrm{HbAlc}$ was done by immunoturbidimetric method. A method used for estimating serum Magnesium, uric acid, hs-CRP was respectively colorimetric method using Xylidyl blue, Uricase-Peroxidase and Immunoturbidimetric. Lipid profile includes total cholesterol, Triglycerides, HDL, LDL, and VLDL. and the methods for estimating the same are CHOD-PAP,GPO, modified PVS and PEGME coupled classic precipitation method (same for HDL and LDL) respectively. VLDL was calculated by Friedewald's and Frederickson formula $(\mathrm{VLDL}=\mathrm{TG} / 5)$.

\section{Statistical Analysis:}

Statistical analysis was carried out by using SPSS software, version 20. Data were expressed as an arithmetic mean SD (standard deviation), a median and maximum and minimum range with respect to their distribution. Differences between groups were analyzed with Student's t tests (for normally distributed variables). The level of significance was set at $<0.05$.

\section{RESULTS:}

Table No -1: Comparison Of Mean And Standard Deviation Of Anthropometric Factors Between Healthy Control And Patients With Type 2 DIM.

\begin{tabular}{|l|l|l|l|l|}
\hline $\begin{array}{l}\text { Anthropo } \\
\text { metric } \\
\text { factors }\end{array}$ & \multicolumn{2}{|l|}{$\begin{array}{l}\text { Healthy controls } \\
(\mathbf{n = 1 0 0 )}\end{array}$} & $\begin{array}{l}\text { Patients with type 2 } \\
\text { DMI(n=100) }\end{array}$ \\
\cline { 2 - 5 } & $\begin{array}{l}\text { Males } \\
(\mathbf{n}=\mathbf{6 1})\end{array}$ & $\begin{array}{l}\text { Females } \\
(\mathbf{n}=\mathbf{3 9})\end{array}$ & $\begin{array}{l}\text { Males } \\
(\mathbf{n}=\mathbf{6 7})\end{array}$ & $\begin{array}{l}\text { Females } \\
(\mathbf{n}=\mathbf{3 3})\end{array}$ \\
\hline Gender & $61 \%$ & $39 \%$ & $67 \%$ & $33 \%$ \\
\hline Age & $39.21 \pm 6.24$ & $51.04 \pm 11.33^{* *}$ \\
\hline
\end{tabular}

$* * \mathrm{p}<0.0001$-compared with healthy subjects.

Table No -2: Comparison Of Mean And Standard Deviation Of Levels Of Lipid Profile Between Healthy Control And Patients With Type 2 DM.

\begin{tabular}{|l|l|l|}
\hline \multirow{2}{*}{ Lipid profile } & $\begin{array}{l}\text { Healthy controls } \\
(\mathbf{n = 1 0 0 )}\end{array}$ & $\begin{array}{l}\text { Patients with type } \\
\text { 2 DM (n=100) }\end{array}$ \\
\cline { 2 - 3 } & Mean \pm SD & Mean \pm SD \\
\hline Cholesterol (mg/dl) & $158.9 \pm 17.8$ & $208.9 \pm 62.8^{* *}$ \\
\hline Triglyceride $(\mathrm{mg} / \mathrm{dl})$ & $137 \pm 27.8$ & $217.7 \pm 119.1^{* *}$ \\
\hline $\mathrm{HDL}(\mathrm{mg} / \mathrm{dl})$ & $47.4 \pm 12.9$ & $42.8 \pm 12.4^{*}$ \\
\hline VLDL $(\mathrm{mg} / \mathrm{dl})$ & $28 \pm 7.1$ & $43.2 \pm 23.9^{* *}$ \\
\hline $\mathrm{LDL}(\mathrm{mg} / \mathrm{dl})$ & $94.2 \pm 89.9$ & $117.5 \pm 33.6^{* *}$ \\
\hline
\end{tabular}

${ }^{*} \mathrm{p}<0.05$ - compared with healthy subjects, **p $<0.0001-$ compared with healthy subjects.

Table No -3: Comparison Of Mean And Standard Deviation Of Levels Of RBS, HbAlC, Uric acid, Magnesium And HS-CRP Between Healthy Control And Patients With Type 2 DM.

\begin{tabular}{|l|l|l|}
\hline $\begin{array}{l}\text { Biochemical } \\
\text { parameters }\end{array}$ & $\begin{array}{l}\text { Healthy controls } \\
(\mathbf{n = 1 0 0 )}\end{array}$ & $\begin{array}{l}\text { Patients with type } \\
\text { 2 DM (n=100) }\end{array}$ \\
\cline { 2 - 3 } & Mean \pm SD & Mean SD \\
\hline RBS (mg/dl) & $98.5 \pm 11.9$ & $285.9 \pm 129.4^{* *}$ \\
\hline $\mathrm{HbAlc} \mathrm{( \% )}$ & $4.8 \pm 0.5$ & $9.2 \pm 2.2^{* *}$ \\
\hline Uric acid (mg/dl) & $4.4 \pm 0.7$ & $6.8 \pm 2.2^{* *}$ \\
\hline Magnesium (mg/dl) & $3.6 \pm 1.4$ & $3.2 \pm 1.10^{*}$ \\
\hline hs-CRP (mg/L) & $1.89 \pm 0.9$ & $10.5 \pm 8.7^{* *}$ \\
\hline
\end{tabular}

$* \mathrm{p}<0.05$ - compared with healthy subjects, $* * \mathrm{p}<0.0001-$ compared with healthy subjects.

The Anthropometric factors between healthy controls and patients with type $2 \mathrm{DM}$ are summarized in table 1 where the age was significantly higher in patients with type $2 \mathrm{DM}$ as compared to healthy controls $(p<0.0001$, Table 1$)$. Females seem to be in fewer percentiles in both healthy controls and patients with type $2 \mathrm{DM}$ as compared with males. (Table 1)

When the mean values of serum lipid profile were compared between healthy controls and patients with type $2 \mathrm{DM}$, serum cholesterol, serum triglycerides, VLDL, LDL showed highly significant difference in patients with type $2 \mathrm{DM}$ as compared with healthy controls $(p<0.0001$, Table 2$)$.However, on comparing HDL between healthy controls and patients with 
type $2 \mathrm{DM}$, the difference seems to be significant. $(p<0.05$, Table 2).

The mean values of RBS, $\mathrm{HbAl}$, uric acid and hs-CRP were highly significant in patients with type $2 \mathrm{DM}$ as compared with healthy controls $(p<0.0001$, Table 3 ). But the mean values of serum magnesium showed significant difference between healthy controls and patients with type $2 \mathrm{DM}(\mathrm{p}<0.05$, Table 3).

\section{DISCUSSION:}

Type $2 \mathrm{DM}$ often has both quantitative and qualitative abnormalities of lipoproteins that are responsible for increased incidence of microvascular and macrovascular complications. Incidence of coronary heart disease with atherogenic dyslipidaemia especially myocardial infarction increases three to four folds higher in type $2 \mathrm{DM}$ patients as compared to non diabetics. ${ }^{31}$ The findings in this study showed that the type $2 \mathrm{DM}$ patients had significantly higher serum cholesterol, triglycerides, LDL and VLDL levels; with significantly low HDL levels when compared with non diabetic cases. Hypertriglyceridemia predisposes the life threatening complications like disbetic ketoacedosis, CHD and lipaemia retinalis in patients with type 2DM. The results of our study were in consistent with the findings given by some others workers. $^{32,33}$ Persistent hyperglycemia results in the glycosylation of all proteins, especially collagen cross linking and matrix proteins of arterial wall. This causes endothelial cell dysfunction, the most contributing factor of atherosclerosis. Also several studies reveal that insulin affects the product ion of apolipoprotein in liver and the enzymatic activity of lipoprotein lipase and cholesterol ester transport protein, the most probable causes of dyslipidemia in DM. In addition to this, the insulin deficiency reduces the activity of hepatic lipase and lipoprotein lipase that causes dyslipidemia in DM. ${ }^{34,35}$

Significant and positive correlation was observed between $\mathrm{HbAl} \mathrm{c}$ and lipid profile (Cholesterol, TGs, LDL, and VLDL) and highly significant and negative correlation was observed between $\mathrm{HbAlc}$ and $\mathrm{HDL}$ in our study which suggests a clear association between hyperglycemia and dyslipidemia in type 2DM patients. Our findings were in association with some authors who suggested that that when the glycemic control ( $\mathrm{HbAlc})$ is much more, than the lipid profile is normal but when the glycemic control (HBAlc) is raised than the level of lipid profile increases. ${ }^{36}$ Thus the risk of cardiovascular events in DM patients may be reduced substantially by improving the glycemic control ( $\mathrm{HbAlc})$.

The apo-B containing particles and small LDL particle are increased in diabetes. Also the development of complications is linked to the accumulation of glycation products in tissue proteins. Proper monitoring of glycemic control involves the measurements of plasma glucose and glycated hemoglobin (HbAlc) which suggests that the importance of glycemic control reflects an improved lipid status.

Our study reveals the elevated level of hs-CRP in type 2DM patients as compared with non diabetics and was in association with other co-workers. ${ }^{37,38}$ Type 2DM has been considered as an inflammatory disease and the process of inflammation plays an important role in the development of diabetes. ${ }^{39}$ Diabetes is one of the risk factor for atherosclerosis. In DM patients, atherosclerotic vascular disease is one of the most important causes of morbidity and mortality. ${ }^{40}$ hs-CRP is involved in the immunological process that triggers vascular remodeling and plaque deposition and is associated with increased risk of CVD's. Also hs-CRP increases with the stage of beta-cell dysfunction and insulin resistance. ${ }^{41}$

In our study the elevated levels of uric acid in type 2DM patients were observed when compared with non diabetic cases. Also highly significant and positive correlation was observed between hs-CRP and uric acid. The result of our study was in association with the studies of some co-authors. ${ }^{42,}$ ${ }^{43}$ High serum uric acid is associated with higher risk of type 2 $\mathrm{DM}$ as it is a factor for peripheral arterial disease, insulin resistance, plays a role in cytokine secretion and is a mediator of endothelial dysfunction and systemic inflammation. ${ }^{44}$ Also elevated serum uric acid contributes to diabetic dyslipidemia which is due to increased vascular damage. ${ }^{45}$

Highly significant and positive correlation was observed between $\mathrm{HbAlc}$ and uric acid in our study. Increased blood glucose inhibits uric acid reabsorption in the proximal tubule and results in altered uric acid levels. ${ }^{46}$

Highly significant and negative correlation between hs-CRP and magnesium was observed in our study. Also in content with other co-workers ${ }^{47,48}$ the relationship of low serum magnesium with dyslipidemia in type 2 DM has been revealed which could be the cause of insulin resistance. There is a reduced tyrosine kinase activity at the insulin receptor levels and results in impaired insulin action and increased insulin resistance. The kidneys possibly lose their ability to retain magnesium during periods of severe hyperglycemia due to osmotic action of glycosuria. Hyperglycemia may alter lipoproteins which could be the contributing factor particularly for CVD's that promotes atherogenesis. ${ }^{47}$

The limitations of present study are: In terms of limitations of this study, firstly the sample size could have been larger and secondly we did not have individual food habits information which may affect lipid levels.

\section{CONCLUSION:}

Diabetes is a disease of self management where patients should strictly follow an appropriate nutrition, regular physical activity and proper medication to achieve a good glycemic control. But the common lipid abnormalities seen during diabetes induces dyslipidemia such as hypercholesterolemia, hypertriglyceridemia, elevated LDL, VLDL, low HDL levels which is seen in our study. This plays an important role in the development of CVD's among diabetes patients. Thus the diabetic patient needs a regular monitoring of lipid profiles and blood glucose. Also elevated levels of hsCRP in our study suggest that hs-CRP could be a better prognosis for CVD's and stroke in diabetic patients. Our study concluded that the hyperuricemia could be a potential marker of metabolic syndrome, dyslipidemia, glucose intolerance, high blood pressure and obesity which are accepted as risk factors for developing CVD's. Our study showed hypomagnesium in diabetic patients that suggest its relationship with some micro and macrovascular complications as CVD's.

\section{RECOMIMENDATIONS:}

Increased physical activity, life style modification focusing on high intake of viscous fibrous diet (such as in oats, cereals etc) , increased intake of omega -3 fatty acids and reduction of saturated fats, trans fats, cholesterol intake are highly recommendable for improving lipid profile in cardiovascular disease. Also weight loss, alcohol intake and smoking cessation are suggested for diabetic patients for reducing the future risk of CVD's. Last but not least, community survey for diabetes is essential to identify uncomplicated diabetic population at an early stage. Meticulous control of blood glucose by treatment and also control of blood pressure are likely to be effective.

\section{Acknowledgment:}

We are highly grateful to those patients of the hospital who volunteered to donate their blood when needed for this project. Our thanks are also to the paramedical staff of the hospital for their assistance in collecting and maintaining blood samples. 
Conflict of Interest:

None.

\section{Source of Funding:}

Self funding was done for the study.

\section{REFERENCES:}

1. Fall $\mathrm{CH}$. The non-industrialized countries and affluence. British Medical Bulletin 2001;60:33-50.

2. WHO.WHO/NCD/NCS/GG.2.2003.

3. National clinical guideline for management in primary and secondary care. Type 2 diabetes. Royal college of physicians.2002; ( 1)-259.

4. Dan L. Longo et al. Harrison's Principles of Internal Medicine. $18^{\text {th }}$ edition, 2012, chapter 344, pages 2995-2998.chapter 77, page 628 .

5. Bijani PK Shah Kokila, Reheja BS. HDL Cholesterol in Diabetes.JAPI 1984;32.

6. Sarkar A, Dash S, Barik BK, Muttigi MS, Kedage V, Shetty JK et al.Copper and Ceruloplasmin levls in relation to total thiols and GST in type 2 diabetes mellitus patients .Ind J Clin Biochem 2010;25:74-76.

7. Solano F, Briganti S, Picardo M, Ghanem G. Hyperpigmenting agents: an update review on biological, chemical and clinical aspects. Pigment Cell Research 2006; 19(6):550-71.

8. The Expert Committee on the Diagnosis and Classification of Diabetes Mellitus: Follow -up report on the diagnosis of diabetes mellitus. Diabetes Care 2003;26:3160-3167.

9. Diabetes. http://.who.int /mediacentre/factsheets/fs $312 /$ en/index.html (accessed Nov 2013)

10. Glycosylated Haemoglobin,HbAlC.http://clinlab-navigator.com/testinterpretations/haemoglobin-alc.html?letter $=\mathrm{h}$ ( (accessed Nov 2013).

11. Michael J, Fowler MD. Microvascular and macrovascular complications of diabetes. Clinical Diabetes 2008;28:277-82.

12. American Diabetes Association. Diagnosis and classification of diabetes mellitus. Diabetes Care 2005;28:37-42.

13. Taskinen MR. Diabeteic dyslipidemia. Atheroscler Suppl 2002;3(1):47-51

14. Mahato RV, Gyawali P, Raut PP, Regmi P, KhelanandPS, Dipendra RP, Gyawali P: Association between glycemic control and serum lipid profile in type 2 diabetic patients: glycated hemoglobin as a dual biomarker. Biomed Res 2011;22(3):375-380.

15. Haffner SM. Lipoprotein disorders associated with type 2 diabetes mellitus and insulin resistance. Am J Cardiol.2002; 90:55-6.

16. Ginsberg HN. REVIEW: Efficacy and mechanisms of action of statins in the treatment of diabetic dyslipidemia. J Clin Endocrionol Metab. 2006; 91:383392.

17. Feldt-Rasmussen B.Is there a need to optimize glycemic control in hemodialyzed diabetic patients. Kidney Int 2006; 70:1392-1394.

18. Stolar M. Glycemic control and complications in type 2 diabetes mellitus. Am JMed 2010; 123(3Suppl):S3-11.

19. Delamater AM. Clinical Use of Hemoglobin Alc to improve diabetes management. Clinical Diabetes 2006;24:6-8

20. Khaw KT, Wareham N. Glycated hemoglobin as a marker of cardiovascular risk. Curr Opin Lipidol 2006; 17:637-43.

21. Di Angelantonio E, Gao P, Khan H, Butterworth AS, Wormser D, Kaptoge S et al Emerging Risk Factors Collaboration. Glycated hemoglobin measurement and prediction of cardiovascular disease.JAMA 2014;311:1225-33.

22. Pfutzner A, Forst T. High-sensitivity C-reactive protein as cardiovascular risk marker in patients with diabetes mellitus. Diabetes Technol Ther.2006; 8(1):28-36.

23. Kertes PJ, Jhonson TM 2007. Evidence based Eye care. Philadelphia. LippincottWilliams \&Wilkins.

24. Nakanishi N, Okamoto M, Yoshida H, Matsuo Y, Suzuki K, Tatara K. Serum uric acid and risk of development of hypertension and impaired fasting glucose or type II diabetes in Japanese male office workers Eur.J.Epidemiol 2003.18:523-30.

25. Adlija Causevic, Sabina Semiz, Amra Macic- Dzankovic,Bakira Cico, Tanja Dujic, Maja Malenica, Tamer Bego. Relevance of uric acid in progression of type 2 Diabetes Mellitus. Bosnian Journal of Basic Medical Sciences 2010; $10(1): 54-59$

26. Pham PC, Pham PM, Pham SV, Miller JM, PhamPT. Hypomagnesia in patients with type 2 diabetes. Clin J Am Son Nephrol 2007;2:366-73.

27. Chaudhary D P, Sharma R, Bansal DD. Implication of magnesium deficiency in type 2 diabetes: A Review. Biol.Trace Elem. Res.,2010;134:119.

28. American Diabetes Association. Diagnosis and classification of diabetes mellitus.Diabetic care 2012;35(1):64-71.

29. National clinical guideline for management in primary and secondary care. Type 2 diabetes. Royal college of physicians 2002 ; ( 1):259.

30. W.H.O. Consultation. Definition, Diagnosis and Classification of diabetes mellitus and its complication. World health organization. Dept. of Noncommunicable disease survillence.WHO/NCD/NCS/99. (2). $1999 ;(1): 49$.

31. Assamang G, Schute H. The prospective Cardiovascular Minister (procam) study; Prevalence of hyperlipidemia in persons with hypertension and/or diabetes mellitus and the relationship to coronary heart disease: American Heart Journal 1988; 116:1713.

32. Samatha P, Venkateswarlu M, Siva Prabodh V. Lipid profile Levels in Type 2 Diabetes Mellitus from the Tribal population of Adilabad in Andhra Pradesh, India. Journal of Clinical and Diagnostic Research 2012;6(4):590-592.

33. Nagila A, Bhatt M, Poudel B, Mahato P, Gurung D, Prajapati S, Arun Kumar, Tamrakar BK. Thyroid Stimulating Hormone and its Correlation with lipid profile in the obese Nepalese population. Journal of Clinical and Diagnostic Research 2008;2:932-937.

34. Elinasri HA, Ahmed AM. Patterns of lipid changes among type 2 diabetes patients in Sudan. East Mediterr Health J2008; 14(2):314-324.

35. Mooradian AD. Dyslipidemia in type 2DM. Nat Clin Pract Endocr Metab 2009; 5:150-159.

36. Andersen GE, Christiansen JS, Mortensen HB, Christiansen kM, Pedersen Bjergasrd L, Kastrup KW, Vestermark S. Serum lipids and lipoproteins in 157 insulin dependent diabetic children and adolescents in relation to metabolic regulation, obesity and genetic hyperlipoproteinemia. Acta Paediatr Scand
1983; 72:361-365.

37. Clearfield MB.C-reactive protein: A new assessment tool for cardiovascular disease.JAOA 2005; 105(9):409-16.

38. Pradhan AD, Manson JE, Naessen T et al. C-reactive protein, interleukin 6 and risk of development type 2 diabetes mellitus.JAMA 2001;286:327-34.

39. Ridker PM, Bassuk SS, Toth PP et al. C-reactive protein and risk of cardiovascular disease: Evidence and clinical application. Curr Atheroscler Rep.2003;5:341-9.

40. Audelin Mc, Genest JJ. Homocysteine and cardiovascular diseases in diabetes mellitus.Atherosclerosis.2001; 159:497-511.

41. Pfutzner A, Forst T. hs-CRP as cardiovascular risk marker in patients with diabetes mellitus.Diabetes Technol Ther.2006;8(1):28-36.

42. Chien KL, Chen MF, Hsu HC, Chang WT, Su TC, Lee YT, Hu FB et al. Plasma uric acid and risk of type 2diabetes in a Chinese community.2008;54:310-316.

43. Doria A, Krolewski AS. Diabetes. Lowering serum uric acid levels to prevent kidney failure. Nat Rev Nephrol 201 1 ; 7:495-6.

44. Kanellis J, DH Kang. Uric acid as a mediator of endothelial dysfunction, inflammation and vascular disease. Nephrol.2005;25:39-42.

45. Fowler M.J. Microvascular and macrovascular complications of diabetes. Clinical diabetes.2008;26(2):77-82.

46. Mahmood Bagherion, Durdi Qujeq, Gholam Reza Bakhshi Khaniniki. Evaluation of serum uric acid and Glutathione levels in Diabetic patients and healthy subjects. Iranian Journal of diabetes and obesity. 2013;5(4):157-162.

47. Nasri H. Lipids in association with serum magnesium in diabetes mellitus patients. Acta Angiol.2006; 124:149.

48. Alvin CP. Harrison's Principles of Internal Medicine. $16^{\text {th }}$ Edition. McGraw-Hill 2005. 